\title{
MATHEMATICAL MODEL FOR BIOLOGICAL CELL DEFORMATION IN A CYLINDRICAL PORE
}

\author{
Maciej Szwast ${ }^{1 *}$, Teresa Suchecka ${ }^{2}$, Wojciech Piątkiewicz ${ }^{1}$ \\ ${ }^{1}$ Warsaw University of Technology, Department of Chemical and Process Engineering, \\ Warynskiego 1, 00-645 Warsaw, Poland \\ ${ }^{2}$ Warsaw University of Life Sciences, Department of Hydraulic Engineering and Environmental \\ Reclamation, Nowoursynowska 166, 02-787, Warsaw Poland
}

\begin{abstract}
Some studies show that cells are able to penetrate through pores that are smaller than cell size. It concerns especially Red Blood Cells but it also may concern different types of biological cells. Such penetration of small pores is a very significant problem in the filtration process, for example in micro- or ultrafiltration. Deformability of cells allows them to go through the porous membrane and contaminate permeate. This paper shows how cells can penetrate small cylindrical holes and tries to assess mechanical stress in a cell during this process. A new mathematical approach to this phenomenon was presented, based on assumptions that were made during the microscopic observation of Red Blood Cell aspiration into a small capillary. The computational model concerns Red Blood Cell geometry. The mathematical model allows to obtain geometrical relation as well as mechanical stress relations.
\end{abstract}

Keywords: cell deformation, red blood cell, cell stamina

\section{INTRODUCTION}

Microfiltration process is well known as an efficient method for large particles (more than $0.1 \mu \mathrm{m}$ ) removal. One can suppose that also microorganisms might be removed in such a process. However, some studies (Abatti, 1997; Discher et al., 1998; Lebleu et al., 2009; Secomb et al., 1998; Secomb et al., 2001; Secomb and Hsu, 1996; Shinde et al., 1999) show that cells of microorganisms whose size is larger than pores' size, go through the membrane. Such a process was also observed during blood plasma separation. In the literature one can find a mathematical approach to this matter, e.g. (Abatti, 1997; Suchecka et al., 2005), where the passing of spherical cells through cylindrical pores or a membrane is described.

Such a process is enabled thanks to elastic properties of cells. Many authors, e.g. (Ye et al., 2011), describe that membrane-walled cells are flexible and can change their shape in the presence of different factors. Some papers, e.g. (Y. Wang et al., 2008), claim that flexibility of cells (not only Red Blood Cells) is one of the determining factors of filterability of cells through small pores.

The aim of this paper is to describe cells' deformation during their passing through the capillary lumen on the example of Red Blood Cells (RBC). The presented mathematical model was developed on the basis of microscopic observation of RBC deformation. 
The purpose of this work is to explain in a mathematical way why some cells go through small pores during filtration.

Red Blood Cell has a shape of a flattened disc, whose diameter is ca. $8 \mu \mathrm{m}$ and height is approx. $2 \mu \mathrm{m}$. However, RBC wall has a specific structure that allows for significant cell deformation ( $\mathrm{Li}$, 2009; Secomb et al., 1998; Secomb et al., 2001). This ability is important when one considers small holes penetration by RBC. It is well known that many factors affect living cells properties. Considering RBC, their properties such as size, volume, flexibility, stamina, etc. depend on their owner's health and diet. This paper considers only average properties of RBC.

We have developed a special test illustrating how RBC penetrates a small capillary. For this test glass capillaries (diameter $0.05-1 \mu \mathrm{m})$ were used. Small pressure $(-0.8$ bar) generated by a vacuum pump was the driving force for cell aspiration into a specially shaped glass capillary. During microscopic attempts, we have observed that RBC did change its shape almost immediately after coming into contact with the capillary entry. $\mathrm{RBC}$ took a shape of a solid whose composition was that of a sphere and a cylinder with half-sphere ending: the former, outside the capillary, while the latter, inside the capillary. This observation is shown in Fig.1.

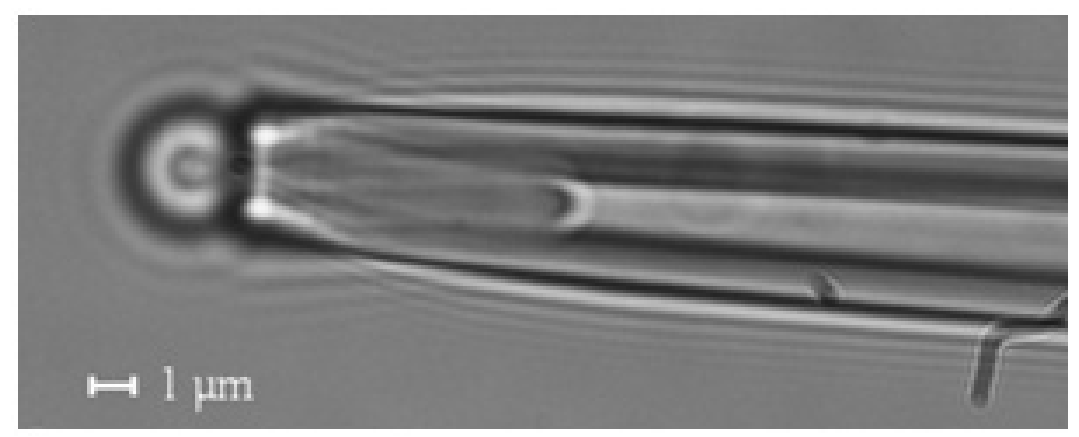

Fig. 1. Microscopic observation of RBC aspiration process

One can find in the literature different approaches to modelling of RBC deformation during small canal passing (Abatti, 1997; Secomb et al., 1998; Secomb et al., 2001; Secomb and Hsu, 1996; Suchecka et al., 2005). Authors assume that cell membrane area is constant during microcapillary aspiration process because of cell's wall properties. We have also made such an assumption. Everyone notes that inside $\mathrm{RBC}$ there is an incompressible fluid. It leads some authors to the conclusion that cell volume is also constant during aspiration. We had proposed in (Suchecka et al., 2005) a different approach, which we developed further in this paper. We believe that during cell deformation pressure inside the cell increases. At the same time, pressure inside capillary is lower than that inside the cell. This is the reason for pressure difference on both sides of cell membrane. This pressure difference is the driving force of cell's liquid filtration through the cell wall. This phenomenon explains why RBC can change its volume during aspiration.

While RBC diameter is ca. $8 \mu \mathrm{m}$, in (Secomb et al., 1998; Secomb et al., 2001; Secomb and Hsu, 1996) one can find deliberations concerning capillaries whose diameter is 3-7 $\mu \mathrm{m}$. Our aim is to show how RBC penetrates holes which are even 10 times smaller than RBC. One can find that in (Abatti, 1997) there are also considerations concerning pores whose diameter is $0.1 \mu \mathrm{m}$. Elsewhere (Abatti, 1997), the author calculated the minimum size of a pore that can be penetrated by cells. He obtained some limitations for pore size, which were calculated using a geometrical model. Our model is also based on geometrical relations, but we assume that cell volume can change (decrease) during aspiration; which fundamentally distinguishes our model from that presented in (Abatti, 1997). Using our model (and neglecting cell membrane thickness), there is only one limitation for holes penetration by cells. This limitation is cell's stamina for mechanical stress. It is also described in this paper. 


\section{MATHEMATICAL MODEL OF ASPIRATION}

For the mathematical model of RBC aspiration the following assumptions were made:

- at the beginning of aspiration, RBC changes its shape into a composition of a sphere and cylinder,

- $\mathrm{RBC}$ wall surface area, $S_{0}$, is constant during aspiration, because RBC wall is non-stretchy (Kuzman et al., 2004),

- $\mathrm{RBC}$ volume, $V_{0}$, is constant during initial shape changes, and varies during the following stages. Volume decreases due to filtration of intercellular liquid through RBC wall,

- taking to calculation literature data (Suchecka et al., 2005): $U F C=3 \cdot 10^{-12} \mathrm{~m}^{2} \cdot \mathrm{s}^{\mathrm{kg}} \mathrm{kg}^{-1}$

- taking to calculation literature data (Bronzino, 2006): $S_{0}=130 \mu \mathrm{m}^{2}$ and $V_{0}=98 \mu \mathrm{m}^{3}$.

Fig.2. shows the assumption about cell shape changes. The symbols used in Fig.2 are also used in the following equations.

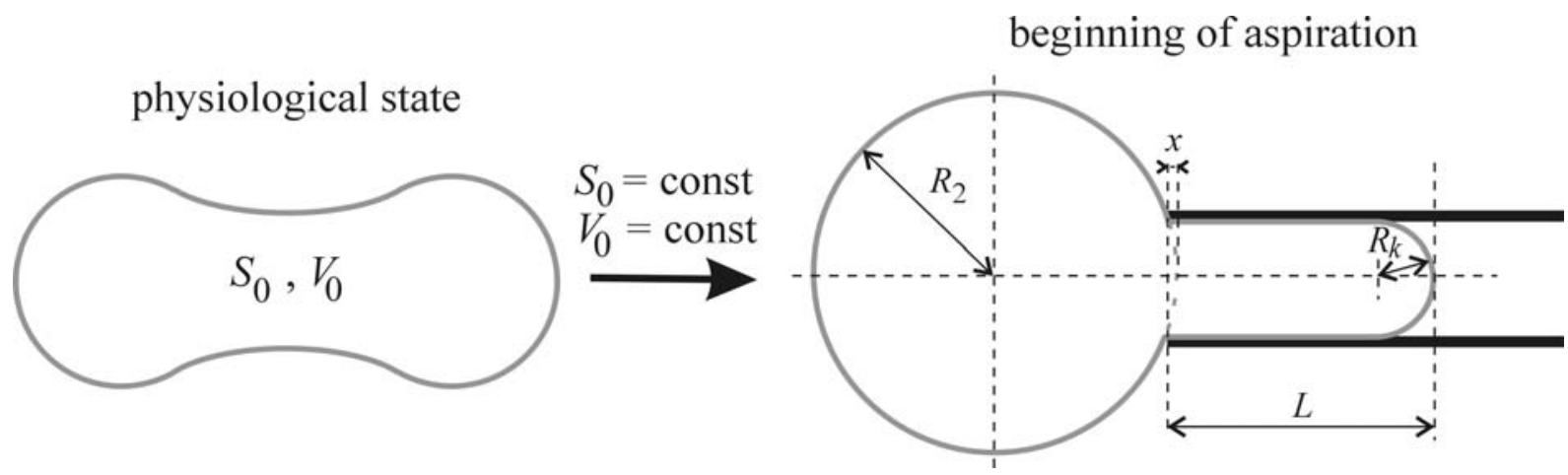

Fig. 2. Graphical interpretation of the model assumption. $L_{0}-$ initial value of variable $L$ defining actual length of the cylindrical part, $R_{0}$ - initial value of variable $R$ defining actual radius of the spherical part, $R_{k}$ - constant capillary radius, $x$ - variable height of the sphere's part

In the face of the defined initial conditions, for the first stage of aspiration one can write down a system of Equations (1) - (2), whose solution gives the initial value of spherical part radius $R_{0}$ and the initial value of cylindrical part length $L_{0}$.

$$
\begin{gathered}
S_{0}=4 \pi R_{0}^{2}-2 \pi R_{0} x+2 \pi R_{k}\left(L_{0}-R_{k}\right)+\frac{1}{2} \cdot 4 \pi R_{k}^{2} \\
V_{0}=\frac{4}{3} \pi R_{0}^{3}-\frac{1}{3} \pi x^{2}\left(3 R_{0}-x\right)+\pi R_{k}^{2}\left(L_{0}-R_{k}\right)+\frac{1}{2} \cdot \frac{4}{3} \pi R_{k}^{3}
\end{gathered}
$$

Furthermore, owing to invariability of surface area $S_{0}$, one can notice that Equation (1) is correct for the whole aspiration process, which means for any $R$ and $L$. However, in Equation (2), for any $R$ and $L$, one has to substitute constant value $V_{0}$ by variable $V$, which is caused by cell volume changes during cell liquid filtration through the cell wall.

Using Pitagoras theorem one can obtain the following relationship, having physical sense, between $x$, $R$ and $R_{k}$, correct for the whole aspiration process:

$$
x=R-\sqrt{R^{2}-R_{k}^{2}}
$$

Because of Equation (3), equation statement (1) - (2) receives a new form:

$$
2 \pi R_{0}^{2}+2 \pi R_{0} \sqrt{R_{0}^{2}-R_{k}^{2}}+2 \pi R_{k} L_{0}-S_{0}=0
$$




$$
\frac{2}{3} \pi R_{0}^{3}+\pi R_{0}^{2} \sqrt{R_{0}^{2}-R_{k}^{2}}-\frac{1}{3} \pi\left(R_{0}^{2}-R_{k}^{2}\right)^{\frac{3}{2}}+\pi R_{k}^{2} L_{0}-\frac{1}{3} \pi R_{k}^{3}-V_{0}=0
$$

Solving equation statement (4) - (5), from Equation (4) one can obtain evident relationship between initial length $L_{0}$, initial radius $R_{0}$ and $R_{k}$.

$$
L_{0}=\frac{S_{0}}{2 \pi R_{k}}-\frac{R_{0}^{2}}{R_{k}}-\frac{R_{0} \sqrt{R_{0}^{2}-R_{k}^{2}}}{R_{k}}
$$

Using Equation (6) in Equation (5) leads to the following relationship:

$$
\frac{2}{3} \pi R_{0}^{3}+\pi R_{0}^{2} \sqrt{R_{0}^{2}-R_{k}^{2}}-\frac{1}{3} \pi\left(R_{0}^{2}-R_{k}^{2}\right)^{\frac{3}{2}}-\pi R_{k} R_{0}^{2}-\pi R_{k} R_{0} \sqrt{R_{0}^{2}-R_{k}^{2}}+\frac{R_{k} S_{0}}{2}-\frac{1}{3} \pi R_{k}^{3}-V_{0}=0
$$

Because of fixed values $S_{0}$ and $V_{0}$, Equation (7) describes unambiguous relationship between the initial value of spherical part radius, $R_{0}$, and capillary radius, $R_{k}$. It is impossible to obtain an easy analytical relationship $R_{0}\left(R_{k}\right)$ due to the form of Equation (7). Therefore, we have decided to obtain a numerical solution. For this purpose a computer application was prepared.

A numerical solution of Equations (6) and (7) permits to obtain charts showing the initial radius of spherical part, $R_{0}$, and the initial length of cylindrical part, $L_{0}$, respectively, as a function of capillary radius, $R_{k}$. It is shown in Fig. 3 and Fig. 4.

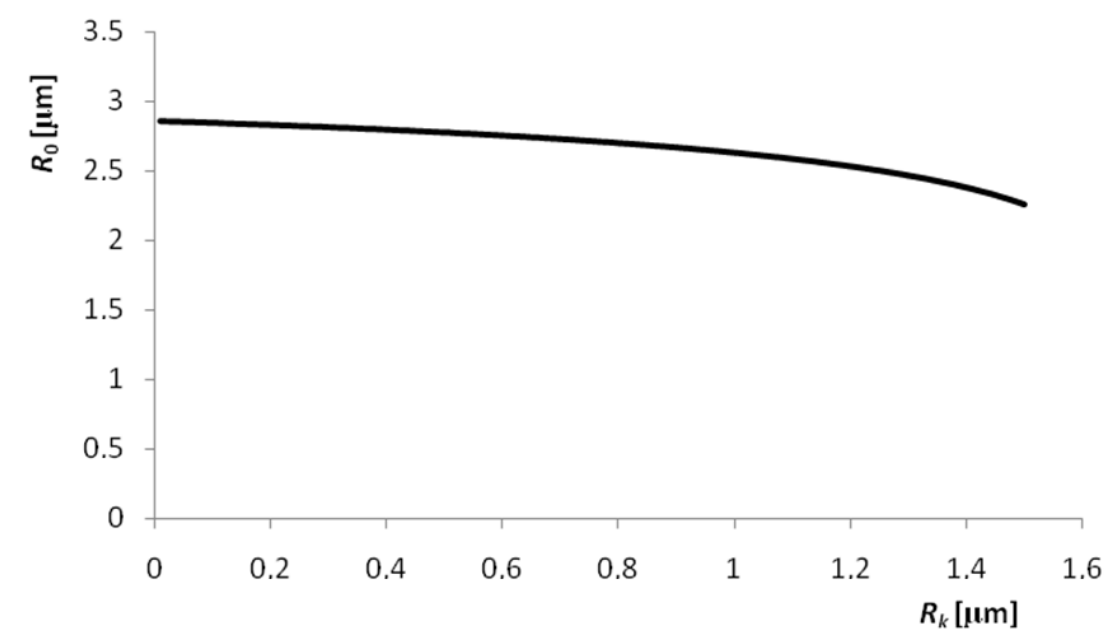

Fig. 3. Radius of cell's spherical part, after the first stage of aspiration, versus capillary radius

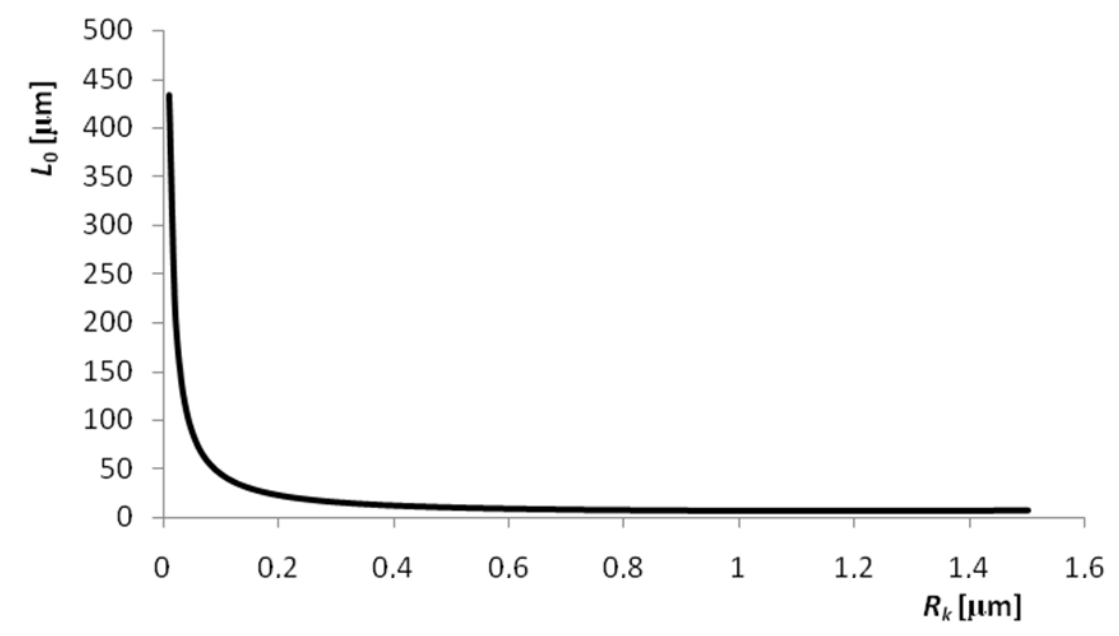

Fig. 4. Length of cell's cylindrical part, after the first stage of aspiration, versus capillary radius 
After the preliminary cell's aspiration into the capillary, because of vacuum present in there, a proper aspiration process begins. The starting point for mathematical model construction is specified by cell wall surface invariability and by the variability of cell volume, which is caused by cell's liquid filtration through the cell wall. In further analysis, the actual spherical part's volume is denoted as $V_{1}$, while the actual cylindrical part's volume is denoted as $V_{2}$. Having the foregoing assumption one can write down the following equation describing the kinetics of the intercellular liquid filtration process (Suchecka et al., 2005):

$$
\frac{d V_{1}}{d t}+\frac{d V_{2}}{d t}=-U C F \cdot \Delta p \cdot S
$$

where: $U F C$ - filtration coefficient, $\Delta p$ - aspiration pressure, $S_{f}$ - filtration surface determined by Equation (15).

The volume of cell's spherical part, which is outside the capillary, can be denoted as:

$$
V_{1}=\frac{4}{3} \pi R^{3}-\frac{1}{3} \pi x^{2}(3 R-x)
$$

This equation, after using Equation (3), will have the following form:

$$
V_{1}=\frac{2}{3} \pi R^{3}+\pi R^{2} \sqrt{R^{2}-R_{k}^{2}}-\frac{1}{3} \pi\left(R^{2}-R_{k}^{2}\right)^{\frac{3}{2}}
$$

However, the volume of cell's cylindrical part, which has been aspirated into the capillary, can be denoted as:

$$
V_{2}=\pi R_{k}^{2}\left(L-R_{k}\right)+\frac{2}{3} \pi R_{k}^{3}
$$

Using the evident relation $L(R)$ described by Equation (6), the foregoing equation will have the following form:

$$
V_{2}=\frac{R_{k} S_{0}}{2}-\pi R_{k} R^{2}-\pi R_{k} R \sqrt{R^{2}-R_{k}^{2}}-\frac{1}{3} \pi R_{k}^{3}
$$

One can observe that the system of Equations (10) and (12) describes volumes $V_{1}$ and $V_{2}$ only as a function of variable $R$.

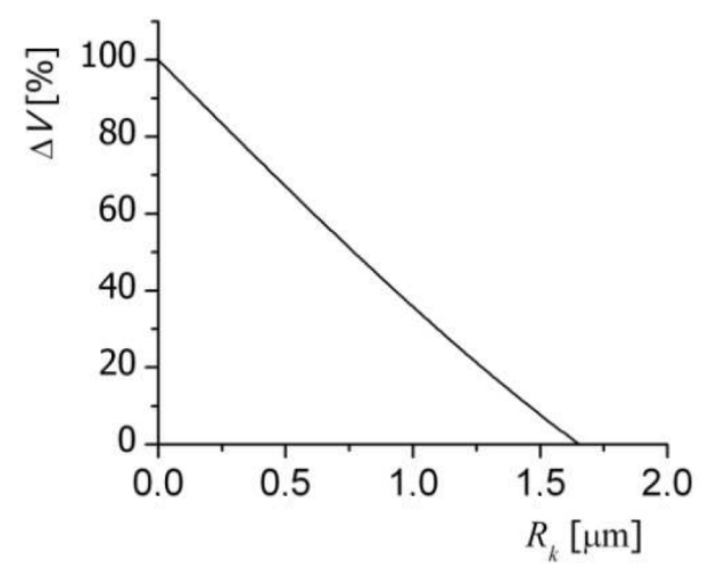

Fig. 5. Cell volume change as a function of capillary radius

Using the model's assumptions which were made earlier (cell's surface area is constant, after total aspiration the cell inside the capillary has a shape of a cylinder ended by semi-spheres), one can obtain 
relationship between cell's volume change, $\Delta V$, and capillary radius. Volume change is defined by Equation (13). The relationship $\Delta V\left(R_{k}\right)$ is shown in Fig. 5.

$$
\Delta V=\frac{V_{0}-V_{k}}{V_{0}}
$$

where $V_{0}$ and $V_{k}$ are initial and final cell volume values respectively.

One can expect that there is a limit value of capillary radius above which aspiration process will be held without volume change. The calculations, as well as Fig. 5, show that the limit value of capillary radius is $1.65 \mu \mathrm{m}$.

Aspiration process kinetic Equation (8) contains derivatives of $V_{1}$ and $V_{2}$ with respect to time, while in Equations (10) and (12) there is only one time-dependent variable $-R$. Therefore, after derivation of Equations (10) and (12) with respect to variable $R$, one can obtain the following system of equations:

$$
\begin{gathered}
\frac{d V_{1}}{d t}=\frac{d V_{1}}{d R} \cdot \frac{d R}{d t}=\left(2 \pi R^{2}+2 \pi R \sqrt{R^{2}-R_{k}^{2}}+\frac{\pi R^{3}}{2 \sqrt{R^{2}-R_{k}^{2}}}-\pi R \sqrt{R^{2}-R_{k}^{2}}\right) \frac{d R}{d t} \\
\frac{d V_{2}}{d t}=\frac{d V_{2}}{d R} \cdot \frac{d R}{d t}=\left(-2 \pi R_{k} R-\pi R_{k} \sqrt{R^{2}-R_{k}^{2}}-\pi R_{k} \frac{R^{2}}{\sqrt{R^{2}-R_{k}^{2}}}\right) \frac{d R}{d t}
\end{gathered}
$$

We assumed that filtration goes only through this part of cell wall that is inside the capillary. That is the place where sub-pressure exists on the outer side of cell wall. Accordingly, filtration surface is represented by the following equation:

$$
S_{f}=2 \pi R_{k}^{2}+2 \pi R_{k}\left(L-R_{k}\right)
$$

Using the evident relation $L(R)$ described by Equation (6), the foregoing equation will have the following form:

$$
S_{f}=S_{0}-2 \pi R^{2}-2 \pi R \sqrt{R^{2}-R_{k}^{2}}
$$

Taking into account Equations (8), (14), (16) and (17), the kinetic equation can be written down in the following form:

$$
\begin{aligned}
& \left(2 \pi R^{2}+2 \pi R \sqrt{R^{2}-R_{k}^{2}}+\frac{\pi R^{3}}{2 \sqrt{R^{2}-R_{k}^{2}}}-\pi R \sqrt{R^{2}-R_{k}^{2}}-2 \pi R_{k} R-\pi R_{k} \sqrt{R^{2}-R_{k}^{2}}+\pi R_{k} \frac{R^{2}}{\sqrt{R^{2}-R_{k}^{2}}}\right) \frac{d r}{d t}= \\
& =-U F C \cdot \Delta p \cdot\left(S_{0}-2 \pi R^{2}-2 \pi R \sqrt{R^{2}-R_{k}^{2}}\right)
\end{aligned}
$$

or after transformation:

$$
\frac{d R}{d t}=\frac{-U F C \cdot \Delta p \cdot\left(S_{0}-2 \pi R^{2}-2 \pi R \sqrt{R^{2}-R_{k}^{2}}\right)}{\left(R-R_{k}\right) \cdot\left(2 \pi R+\pi \sqrt{R^{2}-R_{k}^{2}}+\frac{\pi R^{2}}{2 \sqrt{R^{2}-R_{k}^{2}}}\right)}
$$

Because analytical assignment of function $R(t)$ is impossible, Equation (19) was solved numerically. Knowing relation $R(t)$ one can calculate also relation $L(t)$, where relation $L(R)$ described by Equation (6) is used. 
Numerically appointed relations $R(t)$ and $L(t)$, for different values of $R_{k}$ and for $\Delta p=$ const are shown in Fig. 6, while for different values of $\Delta p$ and for $R_{k}=$.const, in Fig. 7.
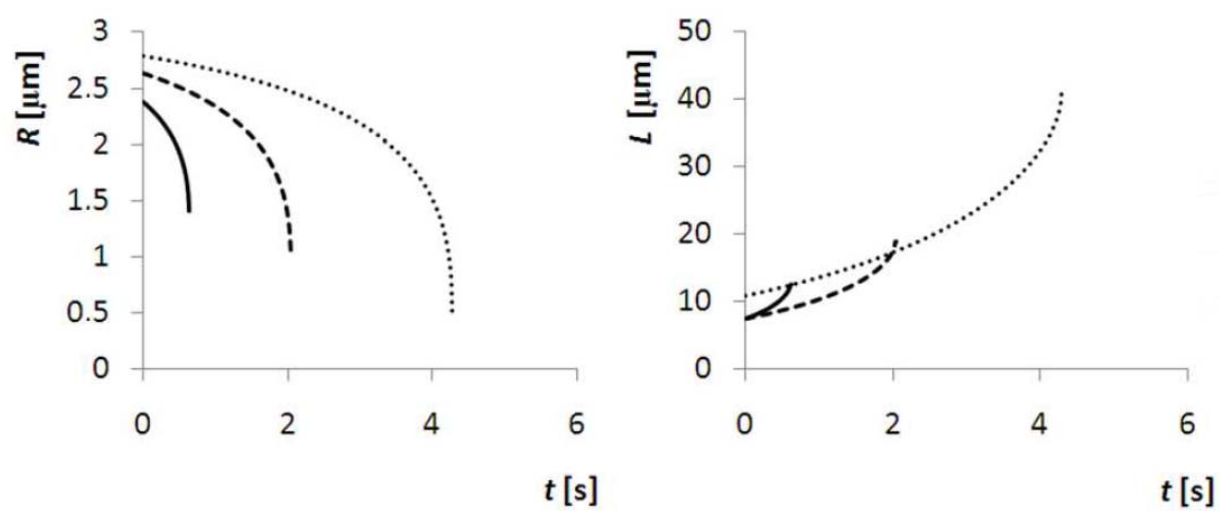

Fig. 6. Relations $R(t)$ and $L(t)$ for different values of capillary radius $R_{k}$ ( $\Delta p=0.5$ bar). Dot line $R_{k}=0.5 \mu \mathrm{m}$, dash line $R_{k}=1.0 \mu \mathrm{m}$, solid line $R_{k}=1.4 \mu \mathrm{m}$
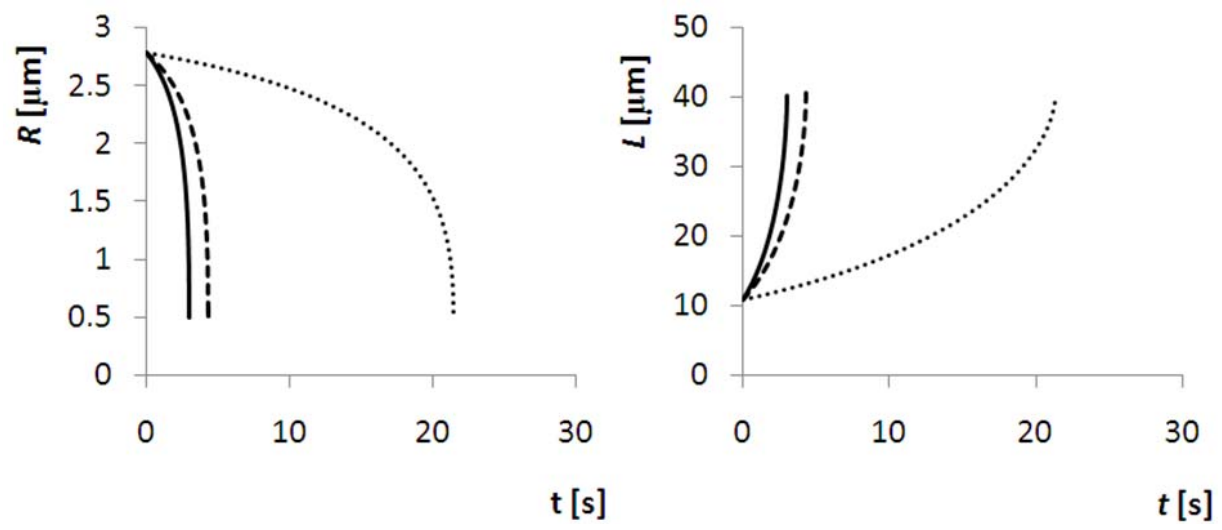

Fig. 7. Relations $R(t)$ and $L(t)$ for different values of aspiration pressure $\Delta p\left(R_{k}=0.5 \mu \mathrm{m}\right)$ : Dot line $\Delta p=0.1$ bar, dash line $\Delta p=0.5$ bar, solid line $\Delta p=0.7$ bar

\section{MECHANICAL STRESS IN CELL'S WALL}

Red Blood Cell aspirated into the capillary is deformed, which means it is exposed to mechanical stresses. Some authors (Bronzino, 2006; Hochmuth 2000) give relationship for the stresses in erythrocyte's wall under deformation. This relationship has the following form:

$$
T=\frac{\Delta p}{2\left(\frac{1}{R_{k}}-\frac{1}{R}\right)}
$$

where $T$ is a stress tensor.

Equation (20) is based on Laplace law and assumes uniform stresses in the whole RBC wall. In our opinion, this equation's usefulness is limited. It is enough to consider two cases, when a cell is totally aspired into the capillary, or when the initial value of cell's radius is equal to capillary radius, i.e. $R=R_{k}$. In such cases stress tensor will have infinite value. Then a cell, as well as other solids, should always break. Observations of aspiration process contradict such a phenomenon.

For determining stress values in cell's wall during RBC aspiration into the capillary, we accept the following reasoning. After the preliminary aspiration, further aspiration process goes thanks to the 
difference between the pressure in the capillary enclosure and the pressure inside the capillary. Effective surface, which this pressure operates on, is the surface of capillary cross section. The driving force inducing aspiration process can be written down as:

$$
F_{\text {asp }}=\Delta p \cdot \pi R_{k}^{2}
$$

For further analysis we have assumed that the cell is divided into three parts. The first of them is a semi-sphere, with radius $R_{k}$, at the end of the cylindrical part inside the capillary. The second one is a cylindrical part inside the capillary. The third one is a part of sphere, with radius $R$, outside the capillary. Due to the semi-spherical shape of the first part, one can admit that stresses in this cell's part are alike on the whole surface. An analogical conclusion refers to the third part. However, the stress value in the first and the third part is not equal. This is a consequence of the presence of cell's liquid, which causes, in accordance with Pascal law, pressure stability in the whole cell, while both cell parts have different radii. Regarding the second, cylindrical, part, stresses in the whole part are the same. Moreover, the second part constitutes a soft prolongation of the first part. In an axial section, the second part's walls lie in the tangential direction of the first part's wall. One can expect that the stress in the second part is close in value to the stress in the first part. However, the transition from the second to the third part is sharp. This place constitutes a notch and is a place of stress heap. Therefore, it is a place of maximal stress, sometimes causing RBC destruction. Further stamina analysis will be reduced to analysis of this place.

Distribution of internal forces in cell's wall, near the capillary entrance, in axial section is shown in Fig. 8.

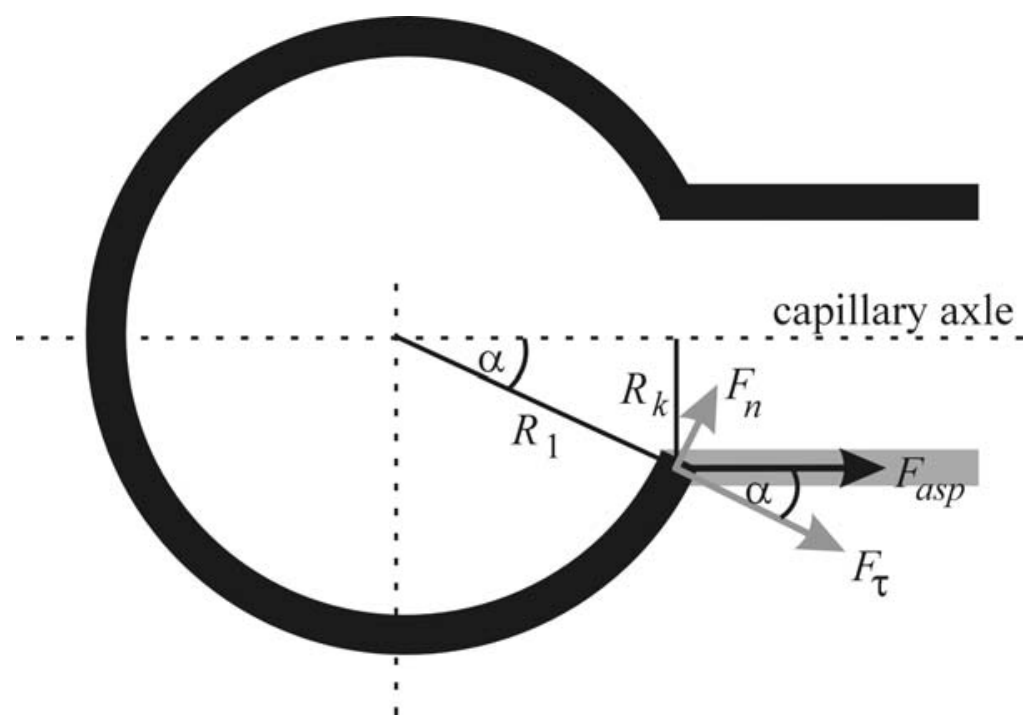

Fig. 8. Distribution of internal forces in cell's wall, near the capillary entrance, in axial section

Analysis of Fig. 8 allows us to ascertain that aggregated forces in normal direction, $F_{n}$, and tangential direction, $F_{\tau}$, can be written down as:

$$
\begin{gathered}
F_{n}=F_{a s p} \frac{R_{k}}{R} \\
F_{\tau}=F_{a s p} \sqrt{1-\left(\frac{R_{k}}{R}\right)^{2}}
\end{gathered}
$$

Indicating cell's wall thickness as $G$, after dividing internal forces by cell's wall cross section area, one can obtain normal stress $\sigma$ and tangential stress $\tau$, respectively: 


$$
\begin{gathered}
\sigma=\frac{F_{a s p} \frac{R_{k}}{R}}{2 \pi R_{k} G}=\frac{\Delta p \cdot \pi R_{k}^{2} \frac{R_{k}}{R}}{2 \pi R_{k} G}=\frac{R_{k}^{2}}{R} \cdot \frac{\Delta p}{2 G} \\
\tau=\frac{F_{a s p} \sqrt{1-\left(\frac{R_{k}}{R}\right)^{2}}}{2 \pi R_{k} G}=\frac{\Delta p \cdot \pi R_{k}^{2} \sqrt{1-\left(\frac{R_{k}}{R}\right)^{2}}}{2 \pi R_{k} G}=\frac{R_{k} \cdot \Delta p \cdot \sqrt{1-\left(\frac{R_{k}}{R}\right)^{2}}}{2 G}
\end{gathered}
$$

Since cell's wall thickness is much smaller than cell's size, one can consider plane stress state.

Considering complex stamina, i.e. where normal and tangential forces appear simultaneously, we have to introduce reduced stress. According to Huber (Mises-Tresca) hypothesis, in plane stress state, reduced stress can be written down as follows:

$$
\sigma_{\text {red }}=\sqrt{\sigma^{2}+3 \tau^{2}}
$$

Putting equations (24) and (25) into equation (26) leads, after transformation, to the following relationship:

$$
\sigma_{r e d}=\frac{R_{k} \Delta p}{2 R G} \sqrt{3 R^{2}-2 R_{k}^{2}}
$$

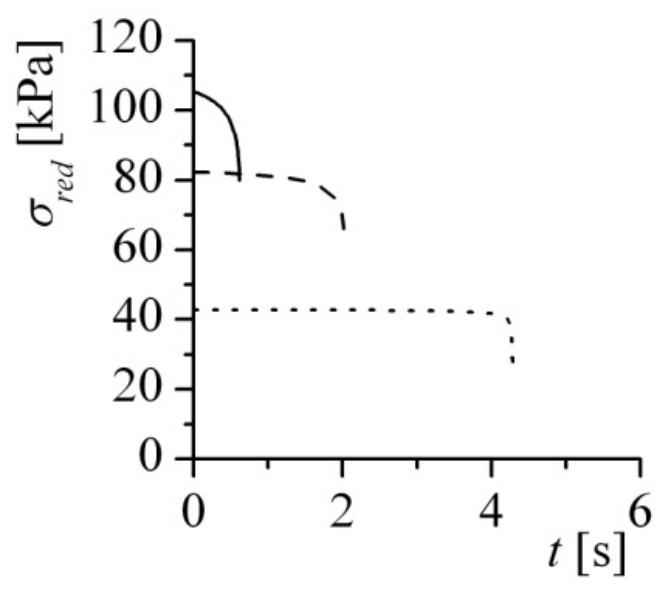

Fig. 9. Relationship $\sigma_{\text {red }}(t)$ for different values of capillary radius $R_{k}(\Delta p=0.5$ bar):

Dot line $R_{k}=0.5 \mu \mathrm{m}$, dash line $R_{k}=1.0 \mu \mathrm{m}$, solid line $R_{k}=1.4 \mu \mathrm{m}$

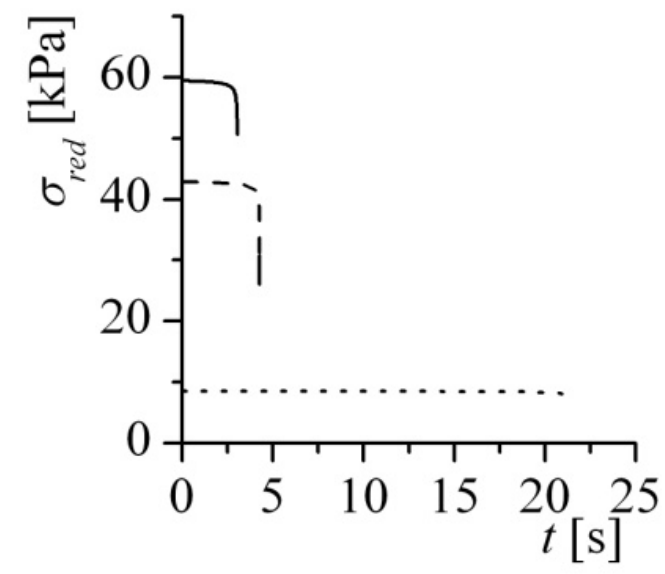

Fig. 10. Relationship $\sigma_{\text {red }}(t)$ for different values of aspiration pressure $\Delta p\left(R_{k}=0.5 \mu \mathrm{m}\right)$ :

Dot line $\Delta p=0.1$ bar, dash line $\Delta p=0.5$ bar, solid line $\Delta p=0.7$ bar 
Using Equation (27) and previously received numerical relationship $R(t)$, one can obtain function $\sigma_{\text {red }}(t)$. Such a relation for different values $R_{k}$ and for $\Delta p=$ const is show in Fig. 9, while for different values $\Delta p$ and for $R_{k}=$ const is shown in Fig. 10 .

Fig. 9 and Fig. 10 indicate different than in literature (Bronzino, 2006; Hochmuth 2000) relation for stress tensor described by Equation (20). Stress in cell's wall is almost constant during the majority of aspiration process and then rapidly decreases to finite value in the final moment of aspiration process. The most important fact is that there is no infinite value of stress, which might lead to cell destruction during aspiration. This conclusion is consistent with experimental studies.

\section{DISCUSSION}

This paper presents a hypothetical mathematical model of cells passing through the small pores. However, we have also provided some laboratory experiments. We have aspired two different cells into the small glass capillaries, which have smaller diameter than the cells' size. The model describes especially Red Blood Cells but we have examined Cryptosporidium parvum oocyst as well. Both of them were completely aspired into the capillary (the cells shapes are indicated by our model) and then pushed out of the capillary without damage. Red Blood Cells as well as Cryptosporidium have the same shape as before the aspiration.

It is important to notice that $\mathrm{RBC}$ has a rather elastic wall while Cryptosporidium has a rigid one. This shows that the presented model is adequate not only for the cells with elastic membrane-walls. Of course Cryptosporidium was aspired into the capillary when the aspiring pressure was quite large (ca. 0.9 bar). Smaller pressures cause only attachment of Cryptosporidium to the capillary inlet; it could be the reason for fouling during filtration.

Having in mind that such a rigid cell as Cryptosporidium is able to go through the small pore, one can expect that pathogenic bacteria with more elastic wall (Escherichia coli, Vibrio cholerae, Helicobacter pyliori) can also go through the microfiltration membrane.

The presented model shows that there are some cases (e.g. pressure) when the cell can pass through the small hole. Knowing this, one can predict filtration parameters at which the cells will be stopped by the membrane, and not pushed through it. This model is helpful in such predictions.

The described model also considers mechanical stresses in the cells during their passing through the small pores. One can state that stresses are quite large so most of the cells will be damaged or will be deactivated. However, in some cases they can still live, which is very important in filtration of water contaminated by dangerous microorganisms.

Considering blood plasma filtration, one can note that at some filtration parameters there is a possibility to have RBC on the permeate side. The presented model also shows what the process conditions are when RBC will be damaged (hemolysis) and haemoglobin will pollute the separated plasma.

\section{CONCLUSIONS}

The mathematical model presented in this paper allows us to understand RBC penetration through microfiltration membranes, for example during plasma separation. The above-described phenomenon was observed in experimental studies. Stamina considerations show that it is possible for RBC to go through the membrane without destruction. One can state that there are some conditions when cell deformation does not cause its break. This model can also be helpful for understanding hemolysis 
process during filtration with high pressures. The presented model can probably be applied to other cells, different than RBC.

\section{SYMBOLS}

$\begin{array}{ll}F_{\text {asp }} & \text { aspiration force, } \mathrm{N} \\ F_{n} & \text { normal force, } \mathrm{N} \\ F_{\tau} & \text { tangential force, } \mathrm{N} \\ G & \text { cell's membrane thickness, } \mathrm{m} \\ L & \text { cell's length inside capillary, } \mathrm{m} \\ p & \text { pressure, } \mathrm{Pa} \\ R & \text { cell's radius outside capillary, } \mathrm{m} \\ R_{k} & \text { capillary radius, } \mathrm{m} \\ S & \text { filtration surface area, } \mathrm{m}^{2} \\ S_{0} & \text { cell's membrane surface area, } \mathrm{m}^{2} \\ t & \text { time, } \mathrm{s} \\ T & \text { stress tensor, } \mathrm{N} \cdot \mathrm{m}^{-1} \\ U F C & \text { filtration coefficient, } \mathrm{m}^{2} \cdot \mathrm{s} \cdot \mathrm{kg}^{-1} \\ V & \text { volume, } \mathrm{m}^{3} \\ V_{0} & \text { initial cell's volume, } \mathrm{m}^{3} \\ V_{k} & \text { final cell's volume, } \mathrm{m}^{3} \\ V_{1} & \text { cell's volume outside capillary, } \mathrm{m}^{3} \\ V_{2} & \text { cell's volume inside capillary, } \mathrm{m}^{3} \\ x & \text { height of the sphere's part, } \mathrm{m}\end{array}$

Greek symbols

$\begin{array}{ll}\alpha & \text { angle, rad } \\ \sigma & \text { normal stress, } \mathrm{Pa} \\ \sigma_{\text {red }} & \text { reduced stress, } \mathrm{Pa} \\ \tau & \text { stress, } \mathrm{Pa}\end{array}$

\section{REFERENCES}

Abatti P.J., 1997. Determination of the red blood cells ability to traverse cylindrical pores. IEEE Trans. Biomed. Eng., 44, 209-212. DOI: 10.1109/10.554767.

Bronzino J.D. (Ed.), 2006. Biomedical engineering fundamentals. Taylor\&Francis, Boca Raton.

Discher D.E., Boal D.H., Boey S.K., 1998. Simulations of the erythrocyte cytoskeleton at large deformation. II. Micropipete aspiration. Biophys. J., 75, 1584-1597. DOI: 10.1016/S0006-3495(98)74076-7.

Hochmuth R.M., 2000. Micropipette aspiration of living cells. J. Biomech., 33, 15-22.

Kuzman D., Svetina S., Waugh R.E., Zeks B., 2004. Elastic properties of the red blood cell membrane that determine echinocyte deformability. Eur. Biophys. J., 33, 1-15. DOI: 10.1007/s00249-003-0337-4.

Lebleu N., Roques C., Aimar P., Causserand C., 2009. Role of the cell-wall structure in the retention of bacteria by microfiltration membranes. J. Membr. Sci, 326, 178-185. DOI: 10.1016/j.memsci.2008.09.049.

Li J., Lykotrafitis G., Dao M., Suresh S., 2007. Cytoskeletal dynamics of human erythrocyte. Proc. Natl. Acad. Sci. USA, 104, 4937-4942. DOI: 10.1073/pnas.0700257104.

Secomb T.W., Hsu R., 1996. Analysis of red blood cell motion through cylindrical micropores: Effects of cell properties. Biohys. J., 71, 1095-1101. DOI: 10.1016/S0006-3495(96)79311-6.

Secomb T.W., Hsu R., Pries A.R., 1998. A model for blood cell motion in glycocalyx-lined capillaries. Am. J. Physiol. Heart Cir. Physiol., 274, H1016-H1022. 
Secomb T.W., Hsu R., Pries A.R., 2001. Motion of red blood cells in a capillary with an endothelial surface layer: effect of flow velocity. Am. J. Physio.l Heart. Circ. Physiol., 281, H629-H636.

Shinde M.H., Kulkarni S.S., Musale D.A., Joshi S.G., 1999. Improvement of the water purification capability of poly(acrylonitrile) ultrafiltration membranes. J. Membr. Sci., 162, 9-22. DOI: 10.1016/S0376-7388(99)00100-3.

Suchecka T., Piątkiewicz W., Sosnowski T.R., 2005. Is the cell retention by MF membrane absolutely safe - a hypothetical model for cell deformation in a membrane pore. J. Membr. Sci., 250, 135-140. DOI: 10.1016/j.memsci.2004.08.035.

Wang Y., Hammes F., Duggelin M., Egli T., 2008. Influence of size, shape, and flexibility on bacterial passage through micropore membrane filters. Environ. Sci. Technol., 42, 6749-6754. DOI: 10.1021/es800720n.

Ye T., Li H., Lam K.Y., 2011. Motion, deformation and aggregation of two cells in a microchannel by dielectrophoresis. Electrophoresis, 32, 3147-3156. DOI: 10.1002/elps.201100240.

Received 18 November 2011

Received in revised form 05 July 2012

Accepted 07 August 2012 